\title{
PERLINDUNGAN HUKUM TERHADAP PENERIMA PINJAMAN DALAM PENYELENGGARAAN FINANCIAL TECHNOLOGY BERBASIS PEER TO PEER LENDING
}

\author{
Agus Priyonggojati \\ Magister Hukum Universitas Semarang, Semarang
}

\begin{abstract}
ABSTRAK
Penelitian ini bertujuan untuk mengkaji dan menganalisa perlindungan hukum terhadap penerima pinjaman dalam penyelenggaran financial technology. Perubahan dalam bidang keuangan saat ini adanya Fintech (Financial Technology) salah satunya Peer to Peer lending. Menjamurnya fintech berbasis peer too peer lending di Indonesia sering menjadi masalah meskipun disisi lain juga jadi jawaban bagi masyarakat yang membutuhkan pendanaan dengan cepat dan mudah. Bahwa terhadap maraknya pinjaman online (Peer to peer Lending) maka pemerintah dalam hal ini adalah OJK ( Otoritas Jasa Keuangan) telah melakukan berbagai cara untuk melindungi masyarakat serta menumbuhkan iklim usaha yang baik namun masalah yang dihadapi masyarakat mash terjadi. Permasalahan dalam penelitian ini adalah Bagaimana proses pelaksanaan penyelenggaraan financial technology berbasis peer to peer lending? Permasalahan permasalahan apa yang timbul dalam penyelenggaraan financial technology berbasis peer to peer lending serta bagaimana solusinya dalam perlindungan hukum terhadap penerima pinjaman dalam penyelenggaraan financial technology berbasis peer to peer lending.Metode penelitian yang digunakan dalam penelitian ini adalah yuridis normative. Penyelenggaraan finansial teknologi yang berbasis peer to peer lending belum berjalan dengan baik. Permasalahan yang timbul dalam penyelenggaraan financial technology berbasis peer to peer lending serta solusinya dalam perlindungan hukum terhadap penerima pinjaman dalam penyelenggaraan financial technology berbasis peer to peer lending belum melindungi masyarakat sehingga perlu adanya peraturan perundang-undangan serta kerjasama semua pihak untuk mewujudkanya.
\end{abstract}

Kata kunci : Perlindungan hukum; pinjaman; peer to peer lending 


\title{
LEGAL PROTECTION FOR LOAN RECIPIENTS IN CONDUCTING FINANCIAL TECHNOLOGY BASED ON PEER TO PEER LENDING
}

\author{
Agus Priyonggojati \\ Master of Law, University of Semarang, Semarang
}

\begin{abstract}
This study aims to examine and analyze the legal protection of loan recipients in the delivery of financial technology. Changes in the current field of finance the existence of the Fintech (Financial Technology) Peer to Peer lending ..progres fintech peer to peer lending in Indonesia often becomes a problem though on the other hand as well so the answer for people who need quick and easy funding. That against rampant online loan (Peer to peer Lending) then the Government in this respect is OJK (Financial Services Authority) has done a variety of ways to protect the public and foster a business climate which is good but the problems encountered mash community occurred. The problem in this research is that the process of implementing the financial technology based peer to peer? lending Problems that which has come up in the financial technology based peer to peer lending and how the solution in legal protection against the loans in the financial technology based peer to peer lending? Research methods that were used in this research was juridical normative.The financial based technology peer to peer lending not run. What problems arose in the financial technology based peer to peer lending and the solution in legal protection on recipients loan in the financial technology based peer to peer lending not protect the public and need ruler to cooperation all parties to mewujudkanya
\end{abstract}

Keywords: legal protection; credit; peer to peer lending 


\section{A. PENDAHULUAN}

Negara Indonesia merupakan negara kepulauan dengan penduduk terbanyak di Asia, memiliki lebih dari 260 juta penduduk yang tersebar di antara 17.000 pulau dan tersebar dari barat ke timur dan dari utara ke selatan.

Kondisi geografis seperti tersebut menimbulkan tantangan dan masalah yang berkaitan dengan aspek pemerataan pembangunan dan perkembangan ekonomi. Permasalahan yang dihadapi salah satunya pemerataan layanan perbankan di Indonesia dalam melaksanakan tugasnya untuk meningkatkan taraf hidup rakyat banyak menjadi salah satu permasalahan. karena hal tersebut diyakini akan mendukung program penanggulangan kemiskinan dan penurunan kesenjangan kemampuan ekonomi masyarakat.

Hal ini terjadi karena berdasarkan letak geogarfis Indonesia yang merupakan negara kepulauan. Jangkauan masyarakat terhadap layanan perbankan menjadi sulit karena perbankan itu sendiri tidak merata. Layanan perbankan hanya tertumpuk di pusat kota saja, kurang menyentuh masyarakat yang ada di pelosok daerah. Hal inilah yang menyababkan kesenjangan kesejahteraan di Indonesia akibat tidak meratanya pembangunan perekonomian nasional.

Bisnis yang dijalankan dalam kegiatan perbankan merupakan kegiatan bisnis yang penuh resiko (full risk business) karena aktivasinya sebagian besar mengandalkan dana titipan masyarakat. Besarnya peran perbankan dalam kegiatan perekonomian harus didukung dengan peraturan yang kuat. Hal tersebut sebagai upaya mewujudkan perbankan yang sehat. ${ }^{1}$.

Namun seiring dengan perkembangan masa di era globalisasi ini, apapun aktivitas masyarakat tidak akan terlepas dari bantuan teknologi. Begitu pula pada lembaga keuangan yang kini mulai bergeser pada lembaga keuangan berbasis teknologi. Salah satu kemajuan dalam bidang keuangan saat ini adanya adaptasi Fintech (Financial Technology)

${ }^{1}$ Zaini Zulfi Diane, Aspek Hukum dan Fungsi Lembaga Penjamin Simpanan, Keni Media, Bandung 2014, hlm. 31 
Bentuk dasar fintech antara lain Pembayaran (digital wallets, P2P payments), Investasi (equity crowdfunding, Peer to Peer Lending), Pembiayaan (crowdfunding, micro-loans, credit facilities), Asuransi (risk management), Lintas - proses (big data analysis, predicitive modeling), Infrastruktur (security).

Kemunculan fintech memunculkan perusahaan-perusahaan keuangan salah satunya dalam bidang layanan pinjam meminjam uang berbasis teknologi informasi (peer-to-peer atau P2P lending). Semakin banyaknya bermunculan perusahaan fintech dalam bidang (peer-to-peer atau P2P lending) tentunya semakin mendapatkan perhatian publik dan pemerintah dalam hal ini regulator yakni Otoritas Jasa Keuangan (OJK) dan Bank Indonesia. Hal tersebut tertuang dalam Peraturan Otoritas Jasa Keuangan Nomor 77/POJK.01/2016 tentang Layanan Pinjam Meminjam Uang Berbasis Teknologi Informasi.

Peraturan OJK Nomor 77/ POJK.01/2016 tersebut belum mampu melindungi masayarakat sehingga hal tersebut berpotensi merugikan masyarakat sehingga bila diibaratkan sepertii madu atau racun, fintech legal bisa dianalogikan dengan madu dan fintech ilegal dianalogikan dengan racun. Keduanya berjalan secara bersamaan menawari pinjaman online kepadamasyarakat. Tetapi, penentu terakhirnya adalah masyarakat yang menikmati layanan itu sendiri, mau minum madu atau racun.

\section{B. PERMASALAHAN}

Berdasarkan latar belakang tersebut diatas, maka dapat dirumuskan permasalahanya sebagai berikut :

1. Bagaimana proses pelaksanaan penyelenggaraan financial technology berbasis peer to peer lending?

2. Permasalahan - permasalahan apa yang timbul dalam penyelenggaraan financial technology berbasis peer to peer lending serta bagaimana solusinya dalam perlindungan hukum terhadap penerima pinjaman dalam penyelenggaraan financial technology berbasis peer to peer lending? 


\section{TINJAUAN PUSTAKA}

\section{Financial Technology}

Di Indonesia fintech telah dikenal luas oleh mayarakat, salah satunya, fintech yang dikenal yaitu Layanan Pinjam Meminjam Uang Berbasis Teknologi Informasi. Mengenai fintech pinjam meminjam telah diatur pada Peraturan Otoritas Jasa Keuangan Nomor 77/POJK.01/2016 tentang Layanan Pinjam Meminjam Uang Berbasis Teknologi Informasi. Pada Pasal 1 Angka 3 POJK 77/POJK.01/2016 menyebutkan bahwa Layanan Pinjam Meminjam Uang Berbasis Teknologi Informasi adalah penyelenggaraan layanan jasa keuangan untuk mempertemukan pemberi pinjaman dengan penerima pinjaman dalam rangka melakukan perjanjian pinjam meminjam dalam mata uang rupiah secara langsung.

\section{Aspek perjanjiaan pada umumnya dan perjanjian pinjam meminjam uang berbasis teknologi informasi.}

Menurut Prof. Subekti dalam bukunya Hukum Perjanjian, "Perjanjian adalah suatu peristiwa di mana seseorang berjanji kepada seorang lain atau di mana dua orang itu saling berjanji untuk melaksanakan sesuat hal ${ }^{2}$

Asas - asas utama Hukum Perjanjian menurut KUHPer ada 5 (lima) yaitu:
a. asas kebebasan berkontrak (freedom of contract)
b. asas konsensualisme (concsensualism)
c. asas kekuatan mengikat (pacta sunt servanda)
d. asas itikad baik (good faith) dan
e. asas kepribadian (personality)

Di dalam KUH Perdata Pasal 1338 menyebutkan "semua perjanjian yang dibuat secara sah berlaku sebagai undang - undang bagi mereka yang membuatnya". Kata"secara sah" berarti memenuhi semua syarat - sayarat yang ditentukan oleh undang undang sedangkan kata "berlaku sebagai undang - undang" berarti mengikat para pihak yang membuatnya.

Munir Fuady mengartikan wanprestasi (defaultatau non fulfilment ataupun yang disebut juga dengan istilah breach of contract) yang dimaksudkan adalah tidak

\footnotetext{
${ }^{2}$ Subekti, Hukum Perjanjian, Jakarta: Intermasa, 2005, hlm. 1
} 
dilaksanakan prestasi atau kewajiban sebagaimana mestinya yang dibebankan oleh kontrak terhadap pihak - pihak tertentu seperti yang disebutkan dalam kontrak yang bersangkutan. ${ }^{3}$

Perjanjian dalam pengaturan KUHPerdata yang dapat mengatur perjanjian pinjam-meminjam uang dibagi kedalam 2 (dua) perjanjian, yaitu perjanjian khusus atau perjanjian bernama atau perjanjian nominaat yang telah diatur secara khusus dalam KUHPer dan Perjanjian innominaat yang timbul berkembang dan tumbuh dalam praktik diluar ketentuan KUHPerdata.

\section{Perlindungan Hukum}

Satjipto Raharjo berpendapat bahwa perlindungan hukum adalah memberikan pengayoman terhadap hak asasi manusia yang dirugikan orang lain dan perlindungan itu di berikan kepada masyarakat agar dapat menikmati semua hakhak yang diberikan oleh hukum. Hukum dapat difungsikan untuk mewujudkan perlindungan yang sifatnya tidak sekedar adaptif dan fleksibel, melainkan juga prediktif dan antisipatif. Hukum dibutuhkan untuk mereka yang lemah dan belum kuat secara sosial, ekonomi dan politik untuk memperoleh keadilan sosial. ${ }^{4}$

Undang Undang Perlindungan Konsumen pada Pasal 2 menyebutkan “ Perlindungan konsumen berasaskan manfaat, keadilan, keseimbangan, keamanan dan keselamatan konsumen serta kepastian hukum.

Bahwa untuk melindungi terhadap penerima pinjaman maka pemerintah melalui OJK (otoritas Jasa keuangan) mengeluarkan Peraturan Otoritas Jasa Keuangan Nomor 77/POJK.01/2016 tentang Layanan Pinjam Meminjam Uang Berbasis Teknologi Informasi dan Peraturan Otoritas Jasa Keuangan Nomor 1/POJK.07/2013 tentang Perlindungan Konsumen Sektor Jasa Keuangan.

\footnotetext{
${ }^{3}$ Munir Fuady, Hukum Kontrak(Dari Sudut Pandang Hukum Bisnis),Bandung,PT.Citra Aditya Bakti,2001, Hal.87

${ }^{4}$ Satjipto Raharjo, Ilmu Hukum, Cetakan Kedelapan, Bandung, PT. Citra Aditya Bakti 2014, hlm 54
} 


\section{PEMBAHASAN}

\section{Proses Pelaksanaan Penyelenggaraan Financial Technology Berbasis Peer To Peer Lending.}

Layanan Pinjam-Meminjam Uang Berbasis Teknologi Informasi atau biasa dikenal Peer to Peer Lending ( P2P Lending) memberikan kemudahan kepada peminjam mendapatkan pinjaman terjangkau dengan proses mudah dan cepat, sedangkan pemberi pinjaman mendapatkan pengembalian berbasis bunga karena telah mendanai pinjaman.

Syarat-syarat yang dilakukan penyelenggara jika ingin menjadi platform penyedia P2P Lending diatur Pada Pasal 2 ayat 1 Peraturan Otoritas Jasa Keuangan Nomor 77 /POJK.01/2016 tentang Layanan Pinjam Meminjam Uang Berbasis Teknologi Informasi (POJK LPMUBTI) bahwa penyelenggara dinyatakan sebagai Lembaga Jasa Keuangan lainya sedangkan badan hukum dari penyelenggara dapat berupa Perseroan Terbatas atau pun koperasi diatur pada Pasal 2 ayat 2 Peraturan Otoritas Jasa Keuangan Nomor 77 /POJK.01/2016 tentang Layanan Pinjam Meminjam Uang Berbasis Teknologi Informasi (POJK LPMUBTI)

Sesuai Pasal 15 ayat 1,2 Peraturan Otoritas Jasa Keuangan Nomor 77 /POJK.01/2016 tentang Layanan Pinjam Meminjam Uang Berbasis Teknologi Informasi (POJKLPMUBTI) yang berbunyi:

1. Penerima Pinjaman harus berasal dan berdomisili di wilayah hukum Negara Kesatuan Republik Indonesia.

2. Penerima Pinjaman sebagaimana dimaksud pada ayat (1) terdiri dari:

a) orang perseorangan warga negara Indonesia; atau

b) badan hukum Indonesia.

Peminjam pada Layanan Pinjam Meminjam Uang Berbasis Teknologi Informasi, syarat utama melakukan perjanjian peer to peer lending adalah itikad baik dalam melakukan perjanjian dan tentu saja cakap dalam melakukan perbuatan hukum. Syarat-syarat yang perlu dilakukan oleh penerima pinjaman 
saat akan bertransaksi dalam platform peer to peer lending adalah mengunggah semua dokumen yang dibutuhkan untuk mengajukan pinjaman secara online (yang relatif cepat prosesnya), yang di antaranya merupakan dokumen berisi identitas diri,foto peminjam, surat keterangan gaji/penghasilan. Permohonan peminjaman dari data penerima pinjaman bisa diterima atau pun ditolak.

Permohonan dari penerima pinjaman ditolak maka penerima pinjaman apabila tetap ingin melakukan transaksi peminjaman maka harus memperbaiki segala hal yang menjadi alasan penolakan permohonan. Faktor yang dapat mempengaruhi adalah kurang lengkapnya dokumen dan informasi yang diisi oleh penerima pinjaman, keakuratan data, dan tidak misleading (menyesatkan). Kemudian, jika diterima, suku bunga pinjaman akan diterapkan dan pengajuan pinjaman penerima pinjaman akan dimasukkan ke dalam marketplace yang tersedia agar semua pemberi pinjaman (lender/investor) bisa melihat pengajuan pinjaman penerima pinjaman. Setelah mendapatkan dana tersebut, peminjam hanya perlu mencicil sesuai dengan ketentuan cicilan dan waktu pengembalian dana.

Bahwa proses penyelengaraan peer to peer lending antara pemberi pinjaman dan penerima pinjaman yang telah sepakat serta telah di tuangkan dalam dokumen elektronik, maka kedua belah telah sesuai dengan syarat sahnya perjanjian pada Pasal 1320 KUHPerdata yaitu kseepakatan, kecakapan,kausa yang halal, hal tertentu. Bahwa perjanjian yang telah disepakati antara pemberi pinjaman dan penerima pinjaman pada penyelengaraan peer to peer lending harus ditaati keduanya hal itu sesuai dalam KUH Perdata Pasal 1338 menyebutkan "semua perjanjian yang dibuat secara sah berlaku sebagai undang - undang bagi mereka yang membuatnya.

Akibat tidak ditaatinya kesepakatan antara pemberi pinjaman dan penerima pinjaman pada penyelengaraan peer to peer lending maka terjadi wanprestasi sehingga pemberi pinjaman dapat memperingatkan kepada penerima pinjaman untuk melaksanakan perjanjiannya namun pada praktiknya penerima pinjaman 
banyak yang tidak memenuhi kewajiban maka pemberi pinjaman melakukan peringatan kepada penerima pinjaman sering melanggar hukum.

Menurut Gustav Radbruch, hukum harus mengandung tiga nilai identitas. (1) Teori Kepastian Hukum atau rechtmatigheid. Teori ini meninjau dari sudut yuridis. (2) Teori Keadilan Hukum (gerectigheit), asas ini meninjau dan sudut filosofis. (3) Teori Kemanfaatan Hukum (zwechmatigheid) atau doelmatigheid atau utility. Teori ini meninjau dari sosiolgis.

Berdasarkan hal tersebut penyelenggaraan financial technology berbasis peer to peer lending belum sesuai dengan peraturan yang ada karena masih banyak pelanggaran atas penyelenggaran financial technology.

\section{Permasalahan Yang Timbul Dalam Penyelenggaraan Financial Technology} Berbasis Peer To Peer Lending Dan Solusinya Dalam Perlindungan Hukum Terhadap Penerima Pinjaman Dalam Penyelenggaraan Financial Technology Berbasis Peer To Peer Lending?

Penyelenggaran finasial technology berbasis peer to peer lending atau yang dikenal dengan Layanan Pinjam Meminjam Uang berbasis teknologi informasi pada praktiknya mengalami banyak masalah sehinga terhadap hal tersebut Pengguna layanan P2P Lending berhak mendapatkan perlindungan hukum dalam melakukan praktek layanan ini, dengan kata lain pemerintah harus menjamin kepastian hukum dalam penyelenggaraan praktek P2P Lending.

Prinsip dasar dalam perlindungan seorang pengguna Layanan Pinjam Meminjam Uang Berbasis Teknologi Informasi adalah bahwa penyelenggara wajib melakukan prinsip-prinsip dasar berupa transparansi, perlakuan yang adil, keandalan, kerahasiaan dan keamanan data, dan penyelesaian sengketa pengguna secara cepat, sederhana, dan biaya terjangkau. Penyelenggara wajib untuk memberikan informasi terkini yang akurat, jujur, jelas dan tidak menyesatkan. Jika ada penerimaan, penundaan, atau penolakan permohonan Layanan Pinjam Meminjam Uang Berbasis Teknologi Informasi penyelenggara wajib untuk menyampaikan informasi tersebut kepada penerima pinjaman. 
Lembaga Bantuan Hukum (LBH) Jakarta meminta agar Otoritas jasa Keuangan segera ikut andil dalam menyelesaikan permasalahn hukum yang menimpa nasabah pinjaman online. Berdasarkan data sementara yang mereka terima dari aduan masyarakat, pinjaman online telah memakan korban sekitar 1.330 korban. $^{5}$

Peraturan untuk mendungi masayarakat telah dikeluarkan dan dijalankan namun, LBH Jakarta mencatat sebanyak 14 pelanggaran hukum dan hak asasi manusia yang dialami oleh korban apllikasi pinjaman online.Pelanggaran pelanggaran tersebut sebagai berikut :

1. Bunga sangat tinggi.

2. Penagihan yang tidak hanya dilakukan pada peminjamn atau kontak darurat yang disertakan oleh peminjam.

3. Ancaman fitnah,penipuan dan pelecehan seksual.

4. Penyebaran data pribadi.

5. Penyebaran foto dan informasi pinjaman ke kontak yang ada pada gawai peminjam.

6. Pengambilan hampir seluruh akses terhadap gawai peminjam.

7. Kontak dan lokasi kantor penyelenggara aplikasi pinjaman online yang tiidak jelas.

8. Biaya admin yang tidak jelas.

9. Aplikasi berganti nama tanpa pemberitahuan kepada peminjam, sedangkan bunga terus berkembang.

10. Peminjam sudah membayar pinjamanya namun pinjaman tidak hapus dengan alasan tidak masuk sistem.

11. Aplikasi tidak bisa dibuka bahkan hilang dari Appstore/Playstore pada saat jatuh tempo pengembalian pinjaman.

12. Penagihan dilakukan oleh orang - orang yang berbeda.

13. Data KTP dipakai oleh penyelenggara aplikasi pinjaman online untuk mengajukan pinjaman diaplikasi lain. 
Virtual account pengembalian uang salah, sehingga bunga terus berkembang dan penagihan intimidatif terus dilakukan. ${ }^{6}$

Upaya pemerintah melalui Satgas Waspada Investasi yang merupakan gabungan Otoritas jasa keuangan (OJK) dan Breskrim Polri serta Kemenkominfo telah memblokir yang tidak terdaftar dan berizin sesuai POJK No.77/POJK.01/2016 sebanyak 1.230 perusahaan finasial teknologi peer to peer lending pada tahun $2018-2019$.

Menurut penadapat Gustav Radbruch, hukum harus mengandung tiga nilai identitas. (1) Teori Kepastian Hukum atau rechtmatigheid. Teori ini meninjau dari sudut yuridis. (2) Teori Keadilan Hukum (gerectigheit), asas ini meninjau dan sudut filosofis. (3) Teori Kemanfaatan Hukum (zwechmatigheid) atau doelmatigheid atau utility serta menurut Fitzgerald menjelaskan teori pelindungan hukum Salmond bahwa hukum bertujuan mengintegrasikan dan mengkoordinasikan berbagai kepentingan dalam masyarakat karena dalam suatu lalu lintas kepentingan, perlindungan terhadap kepentingan tertentu hanya dapat dilakukan dengan cara membatasi berbagai kepentingan di lain pihak

Penyelenggaraan financial technology berbasis peer to peer lending masih muncul permasalahan sehingga perlu danya peraturan perundang - undangan karena peraturan yang ada belum mampu melindungi kepentingan masyarakat serta diperlukan adanya upaya perlindungan hukumnya oleh pemerintah melalui Otoritas Jasa Keuangan (OJK) perlu meningkatkan kewaspadaan,sosialisasi serta mengantisipasi dan menindak terhadap penyelenggara layanan pinjam meminjam uang berbasis layanan teknologi informasi illegal yaitu dengan kerjasama dengan semua komponen yaitu kominfo,polri untuk menertibkan aplikasi yang tidak terdaftar dan tidak berizin sehingga penyelenggaraan financial technology berbasis peer to peer lending ada kepastian hukum,keadilan,kemanfaatan serta perlindungan bagi masyarakat.

${ }^{6} \mathrm{https} / / / \mathrm{m} . h u k u m o n l i n e . c o m / b e r i t a / b a c a / 1 t 5 c 6 a c f 0 c 858 \mathrm{c} /$ pasal-pasal-pidana-yang-bisa-jeratperusahaan-fintech-ilegal/ Akses 25/08/20019 pukul 00.35Wib 


\section{E. PENUTUP}

Penyelenggaraan finansial teknologi yang berbasis peer to peer lending belum berjalan dengan baik sehingga perlu adanya aturan yang jelas karena peraturan yang ada belum memadai agar ada kepastian hukum, keadilan, kemanfaatan Permasalahan yang timbul dalam penyelenggaraan financial technology berbasis peer to peer lending serta perlindungan hukum terhadap penerima pinjaman dalam penyelenggaraan financial technology berbasis peer to peer lending masih muncul permasalahan.

Perlindungan hukum terhadap penerima pinjaman dalam penyelenggaraan financial technology berbasis peer to peer lending serta belum melindungi masyarakat sehingga perlu adanya peraturan perundang- undangan serta adanya kerjasama semua pihak untuk mewujudkanya penyelenggaraan financial technology berbasis peer to peer lending yang baik agar ada kepastian hukum, keadilan, kemanfaatan serta perlindungan bagi masyarakat.

\section{DAFTAR PUSTAKA}

\section{BUKU}

Munir Fuady, Hukum Kontrak (Dari Sudut Pandang Hukum Bisnis),Bandung,PT.Citra Aditya Bakti,2001, Hal.87

Satjipto Raharjo, Ilmu Hukum, Cetakan Kedelapan,, Bandung, PT. Citra Aditya Bakti 2014.

Subekti, Hukum Perjanjian, Jakarta: Intermasa, 2005.

Zaini Zulfi Diane, Aspek Hukum dan Fungsi Lembaga Penjamin Simpanan, Keni Media, Bandung 2014.

\section{INTERNET}

https://m.hukumonline.com/berita/baca/lt5c6acf0c858c/pasal-pasal-pidana-yangbisa-jerat-perusahaan-fintech-ilegal/ Akses 25/08/20019 pukul 00.35Wi http://m.cnnindonesia.com/ekonomi/20181209153903-78-3522422/lbhpidanakanojk-jika-tak-selesaikan-masalah-pinjaman-online,Akses25/08/2019,Pukul 01.13 Wib 